\title{
Benefícios e dificuldades a partir da implementação do SPED: um estudo com profissionais de contabilidade.
}

\author{
Benefits and difficulties from SPED implementation: a study with accounting \\ professionals
}

\begin{abstract}
Antonio Rodrigues Albuquerque Filho Doutorando em Administração e Controladoria. Centro Universitário Estácio do Ceará (FIC) https://orcid.org/0000-0003-2108-3979 Brasil. antoniofilhoufc@hotmail.com

Francisco Johny Rodrigues Lopes Graduando em Ciências Contábeis. Centro Universitário Estácio do Ceará (FIC) - Brasil.

https://orcid.org/0000-0001-8866-0131 fjohnyrl@gmail.com
\end{abstract}

\section{RESUMO}

O estudo teve como objetivo geral identificar os benefícios e dificuldades a partir da implementação do SPED na concepção dos profissionais de contabilidade de Fortaleza/CE. A pesquisa, quantitativa, analisou dados coletados por meio de levantamento aplicado a 140 profissionais de contabilidade da cidade de Fortaleza - CE. Para a análise dos dados utilizaram-se estatísticas descritivas (medidas de tendência central e dispersão) e análise fatorial exploratória (AFE). Os resultados indicaram que, dentre os benefícios identificados após a implementação do SPED, o mais evidenciado pelos profissionais de contabilidade de Fortaleza foi a disponibilização de informações de qualidade, ao passo que a dificuldade mais pontuada foi a falta de conhecimentos sobre os softwares da área. Assim, nota-se a relevância do SPED na contabilização das informações, porém, é necessário que o profissional de contabilidade esteja em constante aperfeiçoamento de suas habilidades, inclusive, a tecnológica. Além disso, tais profissionais, de posse do conhecimento de suas dificuldades quanto ao SPED, podem atenuá-las e consequentemente, contribui com a sociedade na medida que ajudam a cumprir as exigências do fisco em relação aos contribuintes.

Palavras-chave: Benefícios. Dificuldades. SPED.

\begin{abstract}
The general objective of the study was to identify the benefits and difficulties coming from the implementation of SPED (Public System of Digital Bookkeeping) in the perception of accounting professionals in Fortaleza / CE. The quantitative research analyzed data collected through a survey applied to 140 accounting professionals in the city of Fortaleza - CE. For data analysis, descriptive statistics (measures of central tendency and dispersion) and exploratory factor analysis (EFA) were used. The results indicated that, among the benefits identified after the implementation of SPED, the most evidenced by accounting professionals in Fortaleza was the availability of quality information, while the most punctuated difficulty was the lack of knowledge about the software in the area. Thus, the relevance of SPED in accounting for information was verified. However, it is necessary that accounting professionals be in a process of constant improvement of their skills, including the ones in the technological area. In addition, these professionals, being aware of their difficulties in relation to SPED, can mitigate them and, consequently, contribute to society as they help to fulfill the tax requirements in relation to taxpayers.
\end{abstract}

Keywords: Benefits. Difficulty. SPED. 


\section{INTRODUÇÃO}

A aplicação tecnológica tem mudado consideravelmente o modo de conduzir a administração das empresas. Wernke e Bornia (2001) expõe que as companhias estão economicamente alocadas no ambiente de informação reduzida a bits cujos dados estão armazenados em computadores, onde rapidamente são compartilhados por meio da rede de forma digital.

Em virtude desses constantes avanços tecnológicos, nota-se cada vez mais, os impactos causados pela implementação de sistemas digitais nas organizações que visam a redução dos processos manuais, inclusive no âmbito contábil (JORDÃO et al., 2018). De acordo com Sebold et al. (2012), desde a década de 40 a automatização das rotinas existentes tem gerado diversos benefícios econômicos para seus usuários.

Mediante as mudanças tecnológicas a contabilidade reestrutura-se procurando se adaptar, utilizando meios como a reformulação das técnicas e procedimento contábeis, que, diretamente, geram um impacto na forma como as informações e os serviços são oferecidos aos clientes (ORIGUELA, 2017). Citando um exemplo, temos a internet, que hoje, está estritamente ligada às rotinas de trabalho dos escritórios de contabilidade.

Conforme dispõe Wernke e Bornia (2001), a internet oferece ao profissional contábil um conjunto de possibilidades de utilização, destacando entre essas possibilidades a capacidade de downloads por meio da rede. Esse recurso, permite a Receita Federal do Brasil receber diversas obrigações, além de informações e estatísticas importantes ao trabalho diário do profissional contábil. Os autores ainda afirmam que, com o uso desse mecanismo a integração do profissional contábil com o cliente torna-se mais efetiva, tornando assim a possibilidade de participação deste profissional no auxílio.

Com isso, é fundamental para melhorar as relações de trabalho, a incorporação virtual da comunicação para aprimorar como os serviços são prestados, evitando recorrência de processos manuais e desperdício de matéria prima e tempo. Ainda sobre a incorporação virtual da comunicação, Origuela (2017) colocam que, informações importantíssimas são garantidas pela contabilidade, através de seus relatórios, que ainda são subempregados pela intempestividade dos dados que os sistemas de contabilidade geram.

Com o objetivo de suavizar o problema, softwares de gestão são inseridos nas rotinas diárias das entidades para melhorar e facilitar a comunicação entre os diversos setores de uma organização. Com isso, tendo como a finalidade a diminuição da alteridade de informações entre o fisco e o contribuinte, garantindo uma especificação dos dados dispostos aos agentes, e de aprimorar a qualidade das informações solicitadas, surgiu o Sistema Público de Escrituração Digital (SPED), assim, seguindo modelos já antes utilizados, em países como a Espanha, Chile e México (RUSCHEL; FREZZA; UTZIG, 2011).

O governo brasileiro, buscando a informatização dos processos, criou o SPED em 2007 (Decreto n 6.022, de 22 de janeiro de 2007), tendo-o como parte do Programa de Aceleração do Crescimento (PAC) 2007/2010 do governo federal, e do qual é formado basicamente por quatro subsistemas: a Nota Fiscal Eletrônica (NF-e), a Escrituração Fiscal Digital (EFD), a Escrituração Fiscal Digital Social (EFD-Social) e a Escrituração Contábil Digital (ECD).

De acordo com o próprio site da Receita Federal (BRASIL, 2020), a utilização do SPED tem como objetivo a "modernização da sistemática atual do cumprimento das obrigações acessórias". Em termos práticos, as informações serão repassadas ao fisco por meio de arquivos digitais, substituindo o repasse de informações em papel (PASSOS, 2010). Devido a essa melhoria digital, é notório a necessidade de utilização de sistemas digitais para uma análise mais efetiva dos processos que levam ao cumprimento das obrigações, evitando erros e retificações futuras.

No que tange ao SPED, Oliveira (2021) destaca que dentre seus principais benefícios tem-se a padronização de informações contábeis e fiscais, racionalização e uniformização das obrigações acessórias, fiscalização mais efetiva das operações com cruzamento de dados e auditoria eletrônica, além de rapidez no acesso as informações. Mahle e Santana (2009), por sua vez, encontraram evidencias que demostraram que a redução de papel para proteger o meio ambiente e a padronização das informações contábeis foram os principais benefícios evidenciados pela implementação do SPED. Ademais, outros benefícios como a eliminação de digitação de notas fiscais na recepção de mercadorias e a redução de erros de escrituração foram destacadas por Diniz et al., (2009) e Sebold et al. (2012). 
Por outro lado, Origuela (2017) identificaram que a utilização do SPED traz algumas dificuldades como gatos com cursos e treinamentos na perspectiva de aperfeiçoar os profissionais para realização e cumprimento das exigências impostas pelo fisco, mas também o aperfeiçoamento periódico do próprio sistema e adaptação para sua correta geração (Aparecido, 2021). Ademais, conforme Meni (2012) e Jordão et al. (2018), o SPED eleva o custo para as empresas, na medida que sua implementação e aperfeiçoamento constante onera gastos com preparação de equipes internas e clientes. Dessa maneira, o SPED mostra-se relevante para os contribuintes, fisco e consumidores (Aparecido, 2021), neste último, inclui-se os profissionais de contabilidade foco deste estudo.

Assim, em termos gerais, dentro do projeto SPED, o governo disponibiliza programas validadores, softwares próprios da receita federal, que visam a possibilidade do contador ou usuário fazer a apuração das obrigações acessórias. Entretanto, nota-se que dentro desses programas existe uma necessidade operacional de fazer manualmente cada registro, além de uma conferência exaustiva de cada campo informado. Assim, este estudo norteia-se pela seguinte pergunta de pesquisa: Quais os benefícios e dificuldades que surgiram a partir da implementação do SPED na concepção dos profissionais de contabilidade de Fortaleza/CE? Assim, o objetivo geral do estudo consiste em identificar os benefícios e dificuldades que surgiram a partir da implementação do SPED na concepção dos profissionais de contabilidade de Fortaleza/CE.

Portanto, o estudo justifica-se na medida que vê-se a necessidade dos escritórios de contabilidade em meio às buscas pelo aumento da agilidade e a digitalização dos processos, a implementação de sistemas contábeis digitais, assim, o SPED pode ser compreendido como uma mola-mestra que têm influenciado várias áreas, inclusive a contábil que está evoluindo constantemente em decorrência das novas ferramentas computacionais e de comunicação que estão surgindo.

Desse modo, o estudo contribui ao buscar identificar os benefícios e dificuldades após a implementação do SPED na perspectiva dos profissionais de contabilidade, diferenciando-se de outros estudos como os de Mahle e Santana (2009) que focaram na orientação sobre a progressiva implementação do SPED, Silva Filho, Leite Filho e Pereira (2015) que buscou identificar o reflexo da adoção do SPED e o seu impacto sobre os custos operacionais em empresas, Jordão et al. (2018) que analisaram a percepção de contadores e órgãos fiscalizadores federais e estaduais sobre a adoção do sistema público de escrituração digital (SPED), dentre outros. Ademais, o estudo pode ajudar os profissionais de contabilidade, no que se refere a atenuar os possíveis problemas decorrentes da operacionalização do SPED, e isso, refletirá sobremaneira nas atividades que esses profissionais prestam para a sociedade quanto ao cumprimento das exigências do fisco para com os contribuintes.

\section{REFERENCIAL TEÓRICO}

Esta seção traz os posicionamentos teóricos, que servirão de base para o desenvolvimento da linha de raciocínio da pesquisa. Inicialmente, apresentam-se ponderações, sobre a contabilidade digital e Governo eletrônico. Na sequência, trazem-se informações, sobre os sistemas digitais de contabilidade e obrigações acessórias. Por último, evidenciam-se Sistema Público de Escrituração Digital (SPED).

\subsection{1 Contabilidade digital e Governo eletrônico}

O mundo digital está em constante evolução e era esperado que logo entraria nos serviços de contabilidade. As ferramentas digitais melhoraram a técnica dos contadores de elucidar e relatar dados de forma mais rápida e precisa. Esse processo de desenvolvimento deu origem ao que ficou conhecido como contabilidade digital que, de acordo com Lombardo e Duarte (2019) e Jordão et al. (2018), tem como principal objetivo tornar o negócio mais lucrativo e eficiente e do qual os benefícios surgiriam a partir de uma mudança nos processos do escritório. De acordo com esses autores, a contabilidade digital firmou-se em virtude da informatização e automatização das rotinas por meio do ERP (Enterprise Resource Planning) que realizam uma análise mais profunda dos dados e informações e que podem ajudar seus clientes, melhorando os serviços prestados.

Fernandes (2004) afirmam que, para buscar melhores resultados e uma gestão eficaz, a contabilidade deve buscar realizar um diálogo contínuo com os usuários para analisar essas necessidades sobre os dados 
que ele fornece. Assim, possibilita melhora a oferta dos serviços, como a automação, análise de dados, assim como a utilização de ERPs, fazendo com que o profissional contábil dê a devida atenção no auxílio da tomada de decisão de seus clientes (DUARTE, 2009)).

Ademais, a contabilidade digital entrou no âmbito dos processos do governo pela aplicação de técnicas digitais como um esforço para centralizar os dados gerados pelas empresas. Esse processo, ficou conhecido, segundo Silva e Lima (2008), como governo eletrônico e teve como objetivo a otimização da prestação de serviços do governo, o que refletiu na criação do SPED.

Segundo Geron et al.(2011), os avanços na tecnologia da informação e nas comunicações eletrônicas, tendo a Internet como fator importante, têm conectado o mundo, garantindo a expansão da economia para mercados antes restritos. Essas novas tecnologias passaram a cooperar com o governo no desempenho de suas funções. A partir disso, com o ingresso da digitalização dos processos e pelo aspecto de governo eletrônico Helbig, Gil-García e Ferro (2009) ponderam que o governo eletrônico envolve basicamente três tipos de transações: $G 2 G$, quando é uma relação interna ou intergovernamental; $G 2 B$, que se caracteriza por transações entre o governo e fornecedores ou pessoas jurídicas; e G2C, que envolve o governo e cidadão.

O governo eletrônico tornou-se uma importante ferramenta de gestão pública, criando um canal eletrônico contínuo de informação e prestação de serviços à sociedade, além de garantir transparência e controle social. Para que essas melhorias tenham efeito na prática, é necessário aprimorar e modernizar o mecanismo de prestação de serviços. Em particular, a troca de informações permite ao departamento aprender e utilizar os conhecimentos adquiridos, permitindo implementar as boas práticas observadas e evitar perdas (CUNHA; COELHO; PRZEYBILOVICZ, 2017; SEBOLD et al., 2012).

Outros benefícios obtidos com o governo eletrônico são a redução dos custos de gestão pública e o melhor aproveitamento de recursos escassos, pois muitos serviços passaram a ser realizados eletronicamente, pela própria sociedade e a qualquer momento (ARAUJO; REINHARD; CUNHA, 2018; RAMPELOTTO; LOBLER; VISENTINI, 2015). Isso pode reduzir o número de servidores e/ou terceirizados que antes desempenhavam atividades burocráticas (SILVA; LIMA, 2008).

Segundo Fernandes (2004), o tema governo eletrônico tem entrado com destaque na agenda governamental e tem gerado discussões sobre seu significado e impacto na experiência da reforma administrativa. $O$ autor também acredita que, de maneira geral, os conceitos, modelos, tecnologias e métodos relacionados ao governo eletrônico têm o potencial necessário para aplicar as principais diretrizes às reformas da administração pública.

\subsection{Sistemas digitais de contabilidade e obrigações acessórias}

Um sistema pode ser definido, segundo Padoveze (2010), como um conjunto de processos interdependentes em interação. Segundo o autor, no sistema de informação, o conjunto inclui fatores humanos e materiais, tecnologia e recursos financeiros, que são resumidos em ordem lógica para alcançar o processamento de dados e traduzi-lo em informações que permitem que a organização alcance seus objetivos.

Conforme Matarazzo (2010, p. 16) dados são "números ou descrição de objetos ou eventos que, isoladamente, não provocam nenhuma reação no leitor". Dessa forma, a informação é para quem recebe-a, uma comunicação que pode gerar uma reação e uma tomada de decisão geralmente acompanhada de efeitos surpreendentes. Com base nisso, evidencia-se que dados não convertidos e dados que não foram processados adequadamente não terão valor como ferramenta de gerenciamento (NYLÉN; HOLMSTRÖM, 2015).

Nessa perspectiva, para realizar o processo de captura, entrada e conversão de dados em informações gerenciais úteis para o processo de tomada de decisão da organização, surgiram os sistemas de informação (ABRELL et al., 2016; PORTO; BANDEIRA, 2006). Tais sistemas tem evoluído e se adaptado as organizações e vem proporcionado melhorias nos processos de auditoria, de obrigações acessórias, além de torna o trabalho do contador menos custoso e mais eficaz. As informações dispostas nos sistemas, como por exemplo o SPED, possibilitam que seja efetuada uma auditoria de informação, preenchimento automático de registros e facilitação de trabalhos manuais por parte dos contadores (SCHIAVI et al., 2020).

As obrigações acessórias, por sua vez, de acordo com Tavares e Pedra (2013), são atos que servem para garantir o cumprimento das obrigações tributárias, do qual os contribuintes e terceiros assumem a 
obrigação formal de fazer e o de não fazer, para cumprir sua obrigação básica de contribuir para a despesa pública. Portanto, é fácil extrair as chamadas obrigações adicionais que estão intimamente relacionadas às funções básicas da contabilidade, que são seus componentes centrais. A este respeito, o direito acessório é considerado o dever dos contribuintes de cooperar na administração e fiscalização fiscais (TAVARES; PEDRA, 2013).

Ainda, corroborando o autor supracitado, acrescenta-se o disposto no artigo $113, \S 3^{\circ}$, do CTN, "a obrigação acessória, pelo simples fato de sua inobservância, converte-se em obrigação principal relativamente à penalidade pecuniária", ou seja, no descumprimento da obrigação formal ocorrerá o próprio dever principal de pagar.

Portanto, seja porque tem por objetivo garantir o cumprimento das obrigações tributárias, ou se expressa como obrigação de cooperar, seja porque não cumpre o contrato transformando as obrigações adicionais em principal, a correlação entre as chamadas obrigações adicionais e a obrigação básica de contribuir para a despesa pública é muito clara (TAVARES; PEDRA, 2013). Exija-se então, um grande conhecimento técnico do contador prestador das informações para o fisco, em destaque, ao projeto SPED. Considerar uma apuração sem intermédio de um sistema digital de contabilidade, ocorrerá um aumento dos riscos mediante a apresentação de informações que possam estar erradas.

Utilizando somente de seus conhecimentos o contador estará sujeito a erros que podem gerar retificações futuras dos arquivos enviado à Receita Federal, gerando custos pela necessidade da correção das informações e encargos gerados pelo órgão em relação a informação prestada errada, daí a importância da utilização de software, como o SPED, por exemplo.

Baseando-se por um sistema digital (SPED, por exemplo) que aloca os dados prestados por meio de informações automatizadas e integrações via ERP dos clientes, é possível efetuar uma auditoria mais precisa e concreta das informações, além da identificação de erros, utilizando critérios das notas técnicas da Receita Federal. Com isso um sistema digital de contabilidade evitaria erros futuros e até fazendo lançamento automático de informações na base de dados, gerando economia com pessoal, mas também nas operações que poderiam ser mais manuais (RUSCHEL; FREZZA; UTZIG, 2011).

\subsection{Sistema Público de Escrituração Digital (SPED)}

O SPED, de acordo com próprio portal da receita federal, em geral, inclui a modernização do atual sistema de obrigações acessórias, que é transferido dos contribuintes aos órgãos reguladores, por meio de certificados digitais assinando documentos eletrônicos, digitalmente. Assim, como pontuado por Gonçalves et al. (2016), Santos e Gustavo (2005) e Silva Filho, Leite Filho e Pereira (2015), o SPED pode ser entendido como um software que é disponibilizado pela Receita Federal para todas as empresas (de forma análoga) aos programas existentes à época, tais como DIPJ, DACON, DCTF, DIRF, PER/DCOMP).

$O$ universo de atuação do SPED abrange todos os principais processos de uma empresa frente às obrigações acessórias, com exceção de algumas ligadas a caixa econômica. Ele é dividido da seguinte forma: projeto Nota Fiscal Eletrônica, geração da Escrituração Fiscal Digital (ICMS, IPI, Pis/Cofins, Lalur etc.) e Escrituração Contábil Digital. (RUSCHEL; FREZZA; UTZIG, 2011; SANTOS; GUSTAVO, 2005).

O SPED, de acordo com o Guia Prático da Escrituração Fiscal Digital é um "arquivo digital, que contém um conjunto de documentos fiscais e outras informações de interesse das autoridades fiscais estaduais, municipais e da secretaria da Receita Federal do Brasil", bem como os registros de cálculo de impostos relacionados aos negócios e serviços prestados pelo contribuinte.

Segundo Castro (2010), Carvalho et al.,(2016) e Jordão et al. (2018), além de reduzir custos, o contribuinte não precisará mais inserir manualmente todas as informações contidas nas notas fiscais emitidas e recebidas pela empresa. Essas tarefas serão realizadas eletronicamente, obtendo-se os dados contidos no arquivo da nota fiscal eletrônica. $O$ autor também acredita que devido à forma simplificada de entrada e informação dos contribuintes (reduzindo o tempo despendido nas atividades), além de reduzir o número, as obrigações acessórias dos contribuintes também possibilitam a redução de erros humanos cometidos ao realizar tarefas manuais e repetitivas (AZEVEDO; MARIANO, 2010). 
No Brasil, onde grandes extensões de terra e a falta de recursos econômicos são os principais motivos da evasão fiscal, a conversão de pilhas de informações em papel necessárias ao desempenho financeiro para a forma eletrônica ajuda a controlar melhor o endividamento. O SPED pode ser entendido como a principal força de uma verdadeira revolução, que se caracteriza pela transição da contabilidade dos processos manuais e básicos para outro digital e mais ágil. Dessa forma, espera-se que o custo seja reduzido significativamente, a velocidade de processamento seja aumentada e isso ajudará no combate à sonegação fiscal, que é um problema histórico em nosso país (SEBOLD et al., 2012).

Algumas pesquisas já foram realização com o intuito de identificar as características do SPED. Farias (2010), em seu estudo, teve por objetivo analisar a percepção dos contribuintes em relação aos impactos da adoção do SPED nos processos operacionais, assim como a redução de custos das empresas que já estiveram inseridas em algum dos grandes subprojetos do SPED no Estado de São Paulo, além de verificar como são as expectativas e percepções desses contribuintes diante do novo sistema. Os autores identificaram que os contribuintes sinalizaram que com a adoção do SPED houve a redução de tempo na emissão de uma nota fiscal, maior agilidade e produtividade no recebimento de mercadorias, assim como redução na aquisição de papel. Além disso, há uma expectativa que no futuro haja uma redução nos riscos de fraudes e uma diminuição dos custos operacionais.

Ruschel, Frezza e Utzig (2011), por sua vez, buscaram avaliar o impacto do SPED na contabilidade, na busca de identificar quais os desafios e as perspectivas dos profissionais contábeis em frente o SPED. Para tal, foram entrevistados 41 profissionais contábeis, que atuam na sub-região do SINDICONT - Chapecó. Os resultados evidenciaram um impacto positivo do SPED na área contábil decorrente da fidedignidade e qualidade dos dados, pois espera-se que ele proporcione agilidade e rapidez na apresentação dessas dados. Contudo, pontuaram que há uma limitação de profissionais capacitados, aumento do trabalho (considerado um ponto positivo), além da necessidade de domínio sobre o assunto.

\section{PROCEDIMENTOS METODOLOGICOS}

Apresentam-se nesta seção os procedimentos metodológicos que orientam o desenvolvimento do estudo. Assim, esta etapa subdivide-se em quatro partes, sendo elas: classificação do estudo, população e amostra, instrumento da pesquisa e técnicas de análise dos resultados.

\subsection{Classificação do estudo}

Este estudo classifica-se como descritivo, pois buscou identificar os benefícios e dificuldades do pósSPED na concepção dos profissionais de contabilidade de Fortaleza/CE. Gil (2002, p. 46) acredita que esse tipo de pesquisa visa "descrever as características de uma determinada população ou fenômeno para estabelecer uma relação entre variáveis".

Quanto ao procedimento utilizado, caracteriza-se como levantamento. Este tipo de pesquisa é importante porque pode fornecer informações úteis para pesquisas futuras. Martins e Theóphilo (2009) apontaram que, embora as pesquisas possam ser planejadas para estudar a relação entre variáveis, elas também são aplicáveis à análise de fatos e descrições, geralmente para estudar alguns ou todos os tópicos de pesquisa.

Usou-se também métodos quantitativos. Raupp e Beuren (2003) afirmam que a pesquisa quantitativa é diferente da pesquisa qualitativa devido ao uso de métodos estatísticos na coleta e processamento de dados.

\subsection{População e Amostra}

O estudo se restringe aos profissionais de contabilidade que atuam na cidade de Fortaleza/CE que trabalham com o SPED. A coleta de dados ocorreu no período de 15 de outubro de 2020 a 15 de novembro de 2020. A realização da pesquisa teve por base um questionário on-line aplicado via formulário do Google Forms aos profissionais de contabilidade através de uma linha de network, sendo disponibilizado via redes sociais (WhatsApp e Facebook). 
De início, procedeu-se a aplicação do questionário aos profissionais com participação de 20 respondentes (realizou-se um pré-teste) para que ocorresse a validação do entendimento do questionário e que posteriormente foram inclusos aos dados da pesquisa. De posse da validação do questionário, o estudo aplicou o método Bola de Neve, para coleta dos dados, na qual os profissionais de Ciências contábeis enviaram aos seus colegas de profissão conhecidos.

Assim, o questionário foi enviado a 300 profissionais de contabilidade residentes na cidade de Fortaleza/CE. Destes, a pesquisa obteve um total de 144 respondentes, sendo que foram desconsiderados 4 questionários tidos como inadequados visto que apontaram suas respostas em uma única opção, sendo considerados outliers. O formulário eletrônico não permitia que os respondentes deixassem perguntas sem respostas, assim, não apresentou Missing (perguntas sem respostas).

\subsection{Instrumento de Pesquisa}

O questionário utilizado para a coleta das informações foi dividido em duas partes: a primeira foi dedicada à caracterização do perfil dos profissionais de contabilidade que possuía questões referentes a gênero, idade, cargo que ocupa, escolaridade, instituição de ensino (se pública ou privada), tempo de trabalho e frequência de participação em eventos (cursos, congressos, palestras, Workshops etc.). A segunda foi elaborada de acordo com a literatura sobre o SPED, considerando uma escala intervalar de 5 pontos (escala likert). A escala contou com dez itens que variam de discordo totalmente a concordo totalmente ( 1 - discordo totalmente, 2 - discordo parcialmente, 3 - nem concordo nem discordo, 4 - concordo parcialmente e 5 concordo totalmente). Os itens da pesquisa foram adaptados a partir dos estudos Ruschel, Frezza e Utzig (2011), Primak (2009), Pan e Seow (2016) e Silva Filho, Leite Filho e Pereira (2015) sobre a temática conforme destacado no Quadro 1.

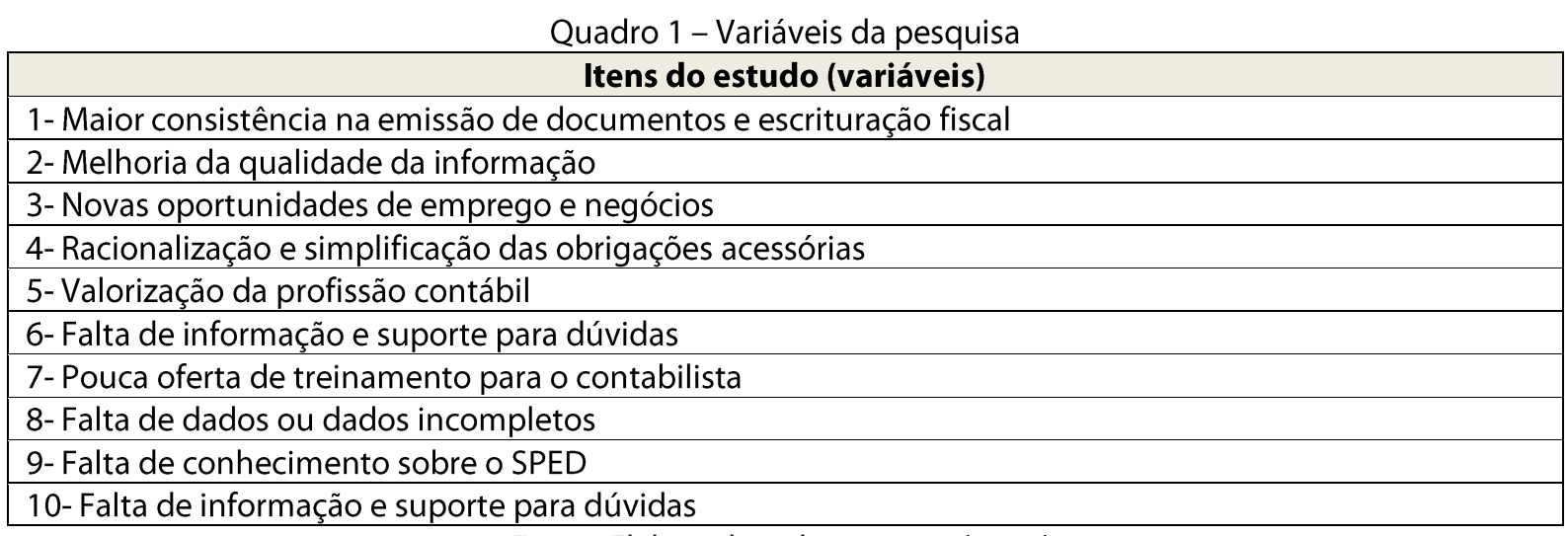

\subsection{Técnica de Análise}

Fonte: Elaborado pelos autores (2021).

Quanto às técnicas utilizadas para a análise dos dados, inicialmente foi realizada análise das características dos respondentes por meio de estatística descritiva, em seguida foi aplicada a Análise Fatorial Exploratória (AFE) por componentes principais e com rotação varimax para identificar a formação das variáveis latentes relacionadas ao construto ao qual pertence (HAIR Jr. et al., 2010). Dessa formar, para validação da AFE aplicou-se as seguintes estatísticas: i) as cargas fatoriais (= ou > 0,5) (HAIR Jr. et al., 2010); ii) Teste de Esfericidade de Bartlett e Kaiser-Meyer-Olkin - KMO (>0,5) (PESTANA; GAGEIRO, 2005); iii) Comunalidade ( $>$ 0,5) (LEE; SAUNDERS; HOOLEY, 2005; HAIR Jr. et al., 2010) e Confiabilidade simples das variáveis observáveis por meio do Alfa de Cronbach (>0,7) (HAIR Jr. et al., 2010).

Ao final, de posse dos resultados da análise fatorial, outras análises foram realizadas, dentre elas, estatísticas univariadas de tendência central e dispersão, que foi utilizada para verificar os benefícios e dificuldades a partir da implementação do SPED mais relevantes na concepção dos profissionais de contabilidade de Fortaleza/CE. Na etapa de tratamento estatístico e análise dos dados, utilizou-se o software SPSS $^{\circledR}$ (Statistical Package for Social Scienses) v.25 para Windows ${ }^{\circledast}$. 


\section{APRESENTAÇÃO E ANÁLISE DOS RESULTADOS}

Esta seção contém a descrição e análise dos dados coletados. Primeiramente, apresenta-se a análise descritiva das características dos respondentes. Na sequência, traz-se a validade e confiabilidade da escala utilizada no estudo. Por último, evidenciam-se o nível médio de cada uma das questões destacadas como benefícios/dificuldades obtidas através da AFE.

\subsection{Perfil dos profissionais de contabilidade}

Iniciam-se os resultados apresentando uma análise do perfil dos profissionais de contabilidade que participaram da pesquisa, assim como apresentado na Tabela 1.

Tabela 1 - Características dos respondentes

\begin{tabular}{cccc}
\hline Variáveis & Classes & Frequência Absoluta & Frequência Relativa \\
\hline \multirow{3}{*}{ Gênero } & Masculino & 81 & $57,9 \%$ \\
& Feminino & 59 & $42,1 \%$ \\
& Total & 140 & $100,0 \%$ \\
& De 21 a 30 anos & 64 & $45,72 \%$ \\
Idade & De 31 a 40 anos & 41 & $29,28 \%$ \\
& De 41 a 50 anos & 13 & $9,28 \%$ \\
& De 51 a 60 anos & 9 & $6,43 \%$ \\
& mais de 61 anos & 13 & $9,28 \%$ \\
& Total & 140 & $100,0 \%$ \\
Cargo que ocupa & Auditor & 20 & $14,3 \%$ \\
& Auxiliar & 30 & $21,4 \%$ \\
& Contador & 28 & $20,0 \%$ \\
& Contador-docente & 13 & $9,3 \%$ \\
& Docente & 13 & $9,3 \%$ \\
Escolaridade & Empresário contábil & 10 & $7,1 \%$ \\
& Outros & 26 & $18,57 \%$ \\
& Doutor & 15 & $10,7 \%$ \\
Instituição & Especialista & 40 & $28,6 \%$ \\
de & Graduação & 67 & $47,9 \%$ \\
ensino & Mestre & 14 & $10,0 \%$ \\
& Pós- doutorado & 4 & $2,9 \%$ \\
Participa de & Total & 140 & $100,0 \%$ \\
eventos & Privada & 88 & $62,9 \%$ \\
& Pública & 52 & $100,0 \%$ \\
& Total & 140 & $40,0 \%$ \\
& Anualmente & 56 & $12,9 \%$ \\
& Mensalmente & 18 & $27,9 \%$ \\
& Não participa & 39 & $9,3 \%$ \\
& Semanalmente & 13 & $10,0 \%$ \\
& Trimestralmente & 14 & $100,0 \%$ \\
\hline \multirow{3}{*}{ Total } & 140 &
\end{tabular}

Fonte: Elaborado pelos autores (2021).

Infere-se pela Tabela 1, que a amostra do estudo apresentou uma participação de 140 profissionais de contabilidade do qual, mais da metade são do gênero masculino (57,9\%). Do total de participantes, as idades concentram-se entre 21 a 30 anos (45,72\%), e dos cargos que ocupam 21,4\% atua como auxiliar, $20 \%$ são contadores e 18,57\% destacam-se em outros cargos abrangendo casos como analista fiscal, analista contábil, analista financeiro, controller, dentre outros.

Em relação ao grau de escolaridade, os profissionais da área de contabilidade prestaram sua formação, em sua maioria, em uma instituição de ensino superior privada $(62,9 \%)$ com titulações divergentes: $28,6 \%$ especialistas, $47,9 \%$ graduados, $10 \%$ mestres, $10,7 \%$ doutores e $2,9 \%$ pós-doutores. É relevante destacar que a 
soma da quantidade de profissionais com doutorado e mestrado equivale a 29 podendo explicar a quantidade de profissionais que atuam como docente ou contador-docente. De forma complementar, quando questionados sobre a frequência em que participam de eventos da área contábil (cursos, congressos, palestras, workshops etc.), a maioria (40\%) participam anualmente, enquanto uma parte significativa (27,9\%) não participa. Em termos gerais, nota-se que é preciso uma maior preocupação por parte dos profissionais da área, na medida que a Norma Brasileira de Contabilidade (NBC PG R1), que trata da educação continuada, requer a atualização constante dos conhecimentos técnicos e profissionais, estimulando suas habilidades e assegurando a qualidade dos serviços prestados por eles.

\subsection{Validade e confiabilidade da escala}

$\mathrm{Na} A F E$, foi examinado o processo e comportamento das variáveis predominantes da escala do estudo por meio dos testes Alfa de Cronbach, Medida Kaiser-Meyer-Olkin de adequação de amostragem (KMO), Teste de Esfericidade de Bartlett, análise de comunalidade e carga fatorial. Para tal, procedeu-se com a rotação Varimax por componentes principais. A Tabela 2 apresenta os resultados da AFE.

Tabela 2 - Variáveis latentes e observáveis - Rotação Varimax - Componentes principais

\begin{tabular}{|c|c|c|c|}
\hline CONSTRUTO & VARIÁVIES & COMUNALIDADES & CARGA FATORIAL \\
\hline & $\begin{array}{l}\text { B1- Maior consistência e confiabilidade na } \\
\text { emissão de escrituração }\end{array}$ & 0,734 & 0,840 \\
\hline BENEFICIOS & B2- Melhoria na qualidade da informação & 0,660 & 0,733 \\
\hline implementação & $\begin{array}{l}\text { B3- Novas oportunidades de emprego e } \\
\text { negócios }\end{array}$ & 0,577 & 0,735 \\
\hline & $\begin{array}{l}\text { B4- Racionalização e simplificação das } \\
\text { obrigações acessórias }\end{array}$ & 0,639 & 0,790 \\
\hline & B5- Valorização da profissão contábil & 0,518 & 0,714 \\
\hline KMC & $=0,830 ; \quad$ Teste de esfericidade de Bartlett $=0,000 ;$ & Alfa Cronbach = & $=0,747$ \\
\hline & D1- Escassez de pessoal qualificado & 0,514 & 0,679 \\
\hline DIFICULDADES a & D2- Falta de informação e suporte de dúvidas & 0,579 & 0,758 \\
\hline $\begin{array}{c}\text { partir da } \\
\text { implementação }\end{array}$ & $\begin{array}{l}\text { D3- Pouca oferta de treinamentos para o } \\
\text { contabilista }\end{array}$ & 0,645 & 0,785 \\
\hline do SPED & D4- Falta de dados ou dados incompletos & 0,702 & 0,823 \\
\hline & $\begin{array}{l}\text { D5- Falta de conhecimento sobre softwares da } \\
\text { área }\end{array}$ & 0,599 & 0,754 \\
\hline & $=0,770 ; \quad$ Teste de esfericidade de Bartlett $=0,000$ & Alfa Cronbach & $=0,817$ \\
\hline
\end{tabular}

Infere-se por meio da Tabela 2, que a análise das variáveis observáveis, foram agrupadas em dois fatores principais (construtos/ variáveis latentes): i) Benefícios a partir da implementação do SPED; e ii) Dificuldades a partir da implementação do SPED. Esses resultados, já eram esperados, visto que as variáveis observáveis foram originadas de pesquisas consolidadas pela literatura especializada. Os dois fatores sinalizaram 61,66\% de explicação acumulada da variância dos dados.

Analisando a confiabilidade dos dados da amostra, o Alfa de Cronbach precisa apresentar uma estatística maior que 0,70 (HAIR Jr et al., 2010). Por meio da Tabela 2, depreende-se que ambos os construtos formados superaram essa estatística, além disso os dados quando analisados em conjunto também apresentou valor superior a 0,70 (0,724), o que sinaliza que a amostra de dados é confiável.

$\mathrm{O}$ teste $\mathrm{KMO}$, por sua vez, estima a medida de adequação dos dados do estudo. Assim, considerando as 10 variáveis observáveis, o teste de KMO apresentou valor igual a 0,830 para o construto "Benefícios a partir da implementação do SPED" e um valor de 0,770 para o fator "Dificuldades a partir da implementação do SPED" que são considerados ótimos (HUTCHESON; SOFRONIOU, 1999). Quanto ao teste de Esfericidade de Bartlett, aparentou significância $\mathrm{p}<0,01$ para os dois construtos e para o grupo de dados que segundo Pestana e 
Gageiro (2005) deve ser menor que 0,05. Portanto, os resultados dos testes confirmam a adequação da análise fatorial, atestando a validade estatística da escala em dois fatores.

Ainda pela Tabela 2, observa-se que as comunalidades superam o valor de 0,5, destacando que pelo menos $50 \%$ da variância de cada uma das variáveis é explicadas por sua carga fatorial, ou seja, são significantes por apresentam resultados superiores a 0,5 (LEE; SAUNDERS; HOOLEY, 2005). Ademais, a carga fatorial das variáveis foi superior a 0,4, não sendo necessário exclusão de alguma das variáveis.

No construto, "Benefícios a partir da implementação do SPED” a questão com maior carga foi a B1 Maior consistência e confiabilidade na emissão de escrituração $(0,840)$, enquanto a questão B5 - Valorização do profissional foi a que apresentou menor carga fatorial $(0,714)$. No construto "Dificuldades a partir da implementação do SPED", a questão D4- Falta de dados ou dados incompletos apresentou a maior carga $(0,823)$, enquanto a D1- Escassez de pessoal qualificado apresentou a menor $(0,679)$.

Com base na Tabela 3, é possível verificar o nível médio de cada uma das questões destacadas como benefícios obtidas através da AFE.

Tabela 3 - Nível médio dos benefícios a partir da implementação do SPED.

\begin{tabular}{|c|c|c|c|c|}
\hline $\begin{array}{c}\text { Benefícios } \\
\text { a partir da implementação do SPED }\end{array}$ & Mínimo & Máximo & Média & $\begin{array}{l}\text { Desvio- } \\
\text { padrão }\end{array}$ \\
\hline $\begin{array}{l}\text { B1- Maior consistência e confiabilidade na emissão de } \\
\text { escrituração }\end{array}$ & 1,0 & 5,0 & 4,173 & 0,8675 \\
\hline B2- Melhoria na qualidade da informação & 1,0 & 5,0 & 4,264 & 0,8449 \\
\hline B3- Novas oportunidades de emprego e negócios & 1,0 & 5,0 & 4,021 & 1,0069 \\
\hline B4- Racionalização e simplificação das obrigações acessórias & 1,0 & 5,0 & 3,657 & 1,2973 \\
\hline B5- Valorização da profissão contábil & 1,0 & 5,0 & 3,671 & 1,0825 \\
\hline
\end{tabular}

Fonte: Elaborado pelos autores (2021).

Por meio da Tabela 3, verifica-se que o principal benefício destacado pelos profissionais de contabilidade foi B2- Melhoria na qualidade da informação que apresentou uma média de 4,264 e desvio padrão de 0,8449. Tal resultado corrobora os estudos de Ruschel, Frezza e Utzig (2011) que identificaram um impacto positivo da utilização do SPED na área contábil por proporcionar dados fidedignos e de qualidade.

A adoção do SPED exigiu das empresas uma maior importância em relação as informações fornecidas ao fisco, tendo em vista que é necessário não apenas validar a documentação, mas também verificar sua qualidade para evitar passivos fiscais futuros ao governo (SILVA FILHO; LEITE FILHO; PEREIRA, 2015).

Por outro lado, o benefício menos destacado foi o B4- Racionalização e simplificação das obrigações acessórias, com média 3,657 e com a maior dispersão (1,2973). Esta última, merece destaque, visto que, segundo o artigo 113, § 30, do CTN, "a obrigação acessória, pelo simples fato de sua inobservância, convertese em obrigação principal relativamente à penalidade pecuniária", o que significa que o profissional de contabilidade deve obter conhecimento técnico, para não incorrer a riscos de repassar informações erradas ao fisco (CASTRO, 2010).

Ademais, apesar deste resultado, houve uma concordância entre os profissionais de contabilidade da amostra, uma vez que todos os benefícios apresentaram nível médio superior a 3,5. Esse achados vai de encontro ao resultados sinalizado por Faria (2010) que identificaram que a redução de tempo na emissão de nota fiscal, maior agilidade e produtividade no recebimento de mercadorias, bem como na redução de papel, são alguns dos pontos evidenciados pelos entrevistados. Ademais, há uma pretensão de que no futuro tenhase uma diminuição dos riscos de fraudes e uma diminuição dos custos operacionais.

Assim, Azevedo e Mariano (2010) destaca que um dos objetivos do SPED consiste em racionalizar e uniformizar as obrigações acessórias e hoje é utilizado como recurso que otimiza a entrega dessas obrigações, armazenando-as em um único banco de dados. A Tabela 4, apresenta as questões das dificuldades obtidas pela AFE. 
Tabela 4 - Nível médio das dificuldades a partir da implementação do SPED.

\begin{tabular}{lrrrr}
\hline \multicolumn{1}{c}{$\begin{array}{c}\text { Dificuldades } \\
\text { a partir da implementação do SPED }\end{array}$} & Mínimo & Máximo & Média & Desvio-padrão \\
\hline D1- Escassez de pessoal qualificado & 1,0 & 5,0 & 2,700 & 1,2847 \\
D2- Falta de informação e suporte de dúvidas & 1,0 & 5,0 & 2,893 & 1,2734 \\
D3- Pouca oferta de treinamentos para o contabilista & 1,0 & 5,0 & 2,700 & 1,3555 \\
D4- Falta de dados ou dados incompletos & 1,0 & 5,0 & 2,525 & 1,3315 \\
D5- Falta de conhecimento sobre softwares da área & 1,0 & 5,0 & 3,193 & 1,2632 \\
\hline
\end{tabular}

Fonte: Elaborado pelos autores (2021).

Pela Tabela 4, depreende-se que, dentre as dificuldades apresentadas, houve uma concordância entre os respondentes, tendo em vista que as médias das perguntas, no geral, apresentam média entre 2,5 a 3 . Entretanto, a questão D5 - Falta de conhecimento sobre softwares da área, apresentou-se como a maior dificuldade enfrentada pelos profissionais de contabilidade com média 3,193 e dispersão de 1,2632. Esse achado coaduna com o estudo de Ruschel, Frezza e Utzig (2011) que encontraram o mesmo resultado só que no contexto da sub-região do SINDICONT - Chapecó. Assim, é relevante destacar que o uso do SPED, possibilita alocar as informações com maior precisão e automaticidade, além de efetuar uma auditoria mais precisa e concreta das informações evitando erros, otimizando tempo e gerando economia de pessoal, mas isso só é possível caso os profissionais estejam capacitados e habilitados para exercerem a profissão, destacando-se nisto a importância da estrutura tecnológica (RODRIGUES; JACINTO, 2011).

Ademais, Rodrigues e Jacinto (2011) ainda apontaram que há uma preocupação dos profissionais da área em estarem capacitados e habilitados para exercer a profissão. Além disso, Amaro Júnior (2010) ponderam que esses profissionais precisam ter uma melhor preparação e qualidade técnica, e para tal, precisam por exemplo, buscar consultoria terceirizada, o SESCON/SINDICONT, além dos sites do portal da Receita Federal e da SEFAZ do estado (RUSCHEL; FREZZA; UTZIG, 2011).

De forma geral, os benefícios mais valorizados pelos profissionais a partir da implementação do SPED foram nesta ordem: i) Melhoria na qualidade da informação; ii) Maior consistência e confiabilidade na emissão de escrituração; iii) Novas oportunidades de emprego e negócios; iv) Valorização da profissão contábil e v) Racionalização e simplificação das obrigações acessórias. As dificuldades a partir da implementação do SPED foram elencadas na ordem: i) Falta de conhecimento sobre softwares da área; ii) Falta de informação e suporte de dúvidas; iii) Escassez de pessoal qualificado e pouca oferta de treinamentos para o contabilista; iv) Falta de dados ou dados incompletos. Portanto, nota-se que os profissionais estão cada vez mais preocupados com a utilização do SPED, e que devido à forma simplificada das informações, além de reduzir os custos, reduz também os erros humanos.

\section{CONSIDERAÇÕES FINAIS}

Com o propósito de identificar os benefícios e dificuldades a partir da implementação do SPED foi aplicado um questionário para 140 profissionais da contabilidade do município de Fortaleza/CE. Para tal, foi feita a análise das questões por meio da análise Fatorial Exploratória (AFE) para examinar o processo e comportamento das questões predominantes da escala do estudo e, por fim, utilizou-se dos construtos formados pela AFE para verificar quais variáveis eram mais relevantes para os profissionais de contabilidade.

A análise dos dados da investigação, permitiu constatar que a partir da escala elaborada com base na literatura especializada, foram formados dois construtos intitulados de "Benefícios a partir da implementação do SPED" e "Dificuldades a partir da implementação do SPED". Com base no construto "Benefícios a partir da implementação do SPED", identificou-se que o benefício mais importante originado do uso do SPED foi a promoção de informações de qualidade, mas também da maior consistência e confiabilidade na emissão de escrituração, ao passo que a racionalização e simplificação das obrigações acessórias foi a menos destacada. No que tange ao fator "Dificuldades a partir da implementação do SPED", evidenciou-se que as maiores dificuldades ocorridas na utilização do SPED foram a falta de conhecimento sobre softwares da área e a falta de informação e de suporte de dúvidas, enquanto a menos incorrida foi a falta de dados ou dados incompletos. 
Portanto, salienta-se que o sucesso do profissional contábil, atualmente encontra-se vinculado ao seu aperfeiçoamento ao máximo, em especial na operacionalização de suas atividades via SPED que norteará a maneira de contabilizar as informações. Ademais, a utilização do SPED é uma exigência por parte do fisco para tornar mais prático e eficiente o registro das informações contábeis. Para tal, ressalta-se a importância de o profissional contábil possuir habilidades como conhecimento tecnológico para obter informação com maior velocidade e precisão, capacidade de análise e síntese das informações e boa comunicação (DUARTE, 2009). Assim, o estudo contribui com os profissionais da área, na medida que permite identificar os possíveis problemas decorrentes da operacionalização do SPED, e isso, refletirá de maneira positiva nas atividades que esses profissionais prestam para a sociedade quanto ao cumprimento das exigências do fisco para com os contribuintes.

Em relação às limitações da pesquisa, destaca-se o instrumento utilizado para a coleta dos dados que foi um questionário enviado via WhatsApp e Facebook, e que houve uma dificuldade em obter a participação dos profissionais da área, contando com a participação de apenas 140 profissionais. Além disso, a pesquisa ficou restrita a este instrumento, visto que outras variáveis poderiam ter sido elencadas pelos profissionais que participaram e neste ponto uma pesquisa qualitativa pode acrescentar com maiores contribuições. Como oportunidades futuras, pode-se considerar, a possibilidade de realizar uma a pesquisa com profissionais de uma outra localidade, utilizando-se de uma outra escala ou mesmo identificar os benefícios e dificuldades após a implementação do SPED sob a perspectiva dos contribuintes e do fisco.

\section{REFERÊNCIAS}

ABRELL, T.; PIHLAJAMAA, M.; KANTO, L.; VOM BROCKE, J.; UEBERNICKEL, F. The role of users and customers in digital innovation: Insights from B2B manufacturing firms. Information \& Management, v. 53, n. 3, p. 324$335,2016$.

AMARO JÚNIOR, F. S. Os impactos tecnológicos da implantação da nota fiscal eletrônica: um estudo de casos múltiplos. 133 f. Dissertação (Mestrado em Administração) - Universidade Federal do Rio Grande do Norte, Natal, 2008.

APARECIDO, João Pedro. AA implantação e os benefícios dos documentos eletrônicos Pós SPED. Revista de Estudos Interdisciplinares do Vale do Araguaia-REIVA, v. 4, n. 01, p. 23-23, 2021.

ARAUJO, Marcelo Henrique de; REINHARD, Nicolau; CUNHA, Maria Alexandra. Serviços de governo eletrônico no Brasil: uma análise a partir das medidas de acesso e competências de uso da internet. Revista de

Administração Pública, v. 52, n. 4, p. 676-694, 2018.

AZEVEDO, O. R.; MARIANO, P. A. Sped - Sistema Público de Escrituração Digital. São Paulo: IOB, 2010.

BRASIL. Ministério da Fazenda. Secretaria da Receita Federal. Sistema Público de Escrituração Digital (Sped): benefícios. Disponível em: Acesso em: 29 out. 2020.

CARVALHO, Hatson Freitas et al. Mudanças na escrituração fiscal: um estudo sobre o impacto e a adaptação dos profissionais contábeis. Revista Eletrônica Gestão e Serviços, v. 7, n. 2, p. 1649-1670, 2016.

CASTRO, M. G. SPED - Sistema Público de Escrituração Digital. SPED - Digital Bookkeeping System, 2010.

CUNHA, Maria A.; COELHO, Taiane R.; PRZEYBILOVICZ, Érico. Get into the club: Positioning a developing country in the international e-gov research. Electronic Journal of Information Systems in Developing Countries. v. 79, n. 4, p. 1-21, 2017.

DINIZ, Eduardo Henrique et al. O governo eletrônico no Brasil: perspectiva histórica a partir de um modelo estruturado de análise. Revista de Administração Pública, v. 43, n. 1, p. 23-48, 2009. 
DRUKER, P. - O futuro já chegou. Artigo do portal Exame. 2001. Disponível em: http://professor.ufop.br/sites/default/files/fred/files/quinta_leitura_revolucao_indstrial.pdf. Acesso em: 06 out. 2020.

DUARTE, R. D. Big Brother Fiscal III: o Brasil na era do conhecimento: como a certificação digital, Sped e NF-e estão transformando a gestão empresarial no Brasil. Belo Horizonte: ideas@work, 2009.

FARIA, A. C. SPED-Sistema Público de Escrituração Digital: Percepção dos contribuintes em relação os impactos da adoção do SPED. [2010]. Disponível em:

https://congressousp.fipecafi.org/anais/artigos102010/248.pdf. Acesso em: 13 abr. 2021.

FERNANDES, A. C. G. Algumas questões para o futuro. In: CHAIN, Ali et al. E-gov.br a próxima revolução brasileira. São Paulo: Prentice Hall, 2004.

GERON, C. M. S. et al. SPED-Sistema Público de Escrituração Digital: percepção dos contribuintes em relação os impactos de sua adoção. Revista de Educação e Pesquisa em Contabilidade, v. 5, n. 2, p. 44-67, 2011.

GIL, A. C. Como elaborar projetos de pesquisa. São Paulo: Atlas, 2002.

GONÇALVES, A. et al. Factors that influence the adoption and implementation of public digital accounting according to the evaluation by managers of brazilian companies. JISTEM-Journal of Information Systems and Technology Management, v. 13, n. 2, p. 193-218, 2016.

HAIR Jr. J. F.; BLACK, W. C.; BARDIN, B. J.; ANDERSON, R. E. Multivariate data analysis. 7. ed. New Jersey: Prentice Hall, 2010.

HELBIG, N.; GIL-GARCÍA, J. R.; FERRO, E. Understanding the complexity of electronic government: Implications from the digital divide literature. Government information quarterly, v. 26, n. 1, p. 89-97, 2009.

HUTCHESON, G. D.; SOFRONIOU, N. The multivariate social scientist: Introductory statistics using generalized linear models. Thousand Oaks, CA: Sage Publications, 1999.

JORDÃO, Ricardo Vinícius Dias et al. Inovações Organizacionais e de Negócios Trazidas pelo SPED: Um estudo empírico sobre as perspectivas de contadores e órgãos fiscalizadores. Revista de Administração da UFSM, v. 11, n. 4, p. 793-811, 2018.

LEE, N.; SAUNDERS, J.; HOOLEY, G. The evolution of "classical mythology" within marketing measure development. European Journal of Marketing, v. 39, n. 4, p. 365-385, 2005.

LOMBARDO, M.; DUARTE, R. D. Contabilidade Online x Contabilidade Digital. 2019. Disponível em: https://robertodiasduarte.com.br/Contabilidade-Online-x-Contabilidade-Digital.pdf. Acesso em: 13 abr. 2021.

MAHLE, Marciane Maria; SANTANA, Alex Fabiano Bertollo. Sistema público de escrituração digital-SPED: um estudo nos escritórios de contabilidade no município de Pinhalzinho/SC. Revista Catarinense da Ciência Contábil, v. 8, n. 23, p. 73-92, 2009.

MARTINS, G. D. A.; THEÓPHILO, Carlos Renato. Metodologia da investigação cientifica para Ciências Sociais aplicadas. 2. ed. São Paulo: Atlas, 2009.

MATARAZZO, D. C. Análise Financeira de Balanço. 7. ed. São Paulo: Atlas, 2010.

PADOVEZE, Clóvis Luís. Contabilidade gerencial: um enfoque em sistema de informação contábil. 7. ed. São Paulo: Atlas, 2010.

MENI, C. SPED: mais custo para empresas. 2012. Disponível em: http://www.incorporativa. com.br/mostranews.php?ctg=8\&id=7633. Acesso em: 18 fev. 2021. 
NYLÉN, Daniel; HOLMSTRÖM, Jonny. Digital innovation strategy: A framework for diagnosing and improving digital product and service innovation. Business Horizons, v. 58, n. 1, p. 57-67, 2015.

OLIVEIRA, F. R. SPED: as teletelas do contribuinte. Disponível em: http:// www.revistarazaocontabil.com.br/index.php?option. Acesso em: 17 fev. 2021.

ORIGUELA, Leticia Aparecida. Os Principais Impactos do SPED na Profissão Contábil: Uma Análise da Percepção dos Profissionais de Contabilidade. Caderno Profissional de Administração da UNIMEP, v. 7, n. 1, p. 45-62, 2017.

PAN, G.; \& SEOW, P. S. Preparing accounting graduates for digital revolution: A critical review of information technology competencies and skills development. Journal of Education for Business, v. 91, n. 3, p. 166-175, 2016.

PASSOS, G. R. P. Sped - Sistema Público de Escrituração Digital: um novo paradigma em termos de conformidade tributária. Dissertação (Mestrado em Ciências Contábeis) - Fundação Escola de Comércio Álvares Penteado (Fecap), São Paulo, 2010.

PESTANA, M. H.; GAGEIRO, J. N. Descobrindo a regressão: com a complementaridade do SPSS. Lisboa: Edições Sílabo, 2005.

PORTO, M. A. G.; BANDEIRA, A. A. A importância dos sistemas de informações gerenciais para as organizações. In: SIMPÓSIO DE ENGENHARIA DE PRODUÇÃO, 13., 2006, Bauru. Anais [...]. Bauru: UNESP, 2006. p. 1-12. Disponível em: https://simpep.feb.unesp.br/anais/anais 13/artigos/974.pdf. Acesso em: 13 abr. 2021.

PRIMAK, F. V. Informaticidade: A Contabilidade na era da informática. 1. ed. Rio de Janeiro: Ciência Moderna, 2009.

RAMPELOTTO, Alexandre; LOBLER, Mauri Leodir; VISENTINI, Monize Sâmara. Avaliação do sítio da Receita Federal do Brasil como medida da efetividade do governo eletrônico para o cidadão. Revista de

Administração Pública, v. 49, n. 4, p. 959-984, 2015

RAUPP, F. M.; BEUREN, I. M. Metodologia da pesquisa aplicável às ciências sociais BEUREN, I. M (org.). Como Elaborar Trabalhos Monográficos em Contabilidade: teoria e prática. 3. ed. São Paulo: Atlas, 2009. p. 7696.

RODRIGUES, J. R. M. C.; JACINTO, M. S. Escrituração contábil digital, a transparência das informações e o perfil do profissional contábil. Humanae, v. 1, n. 4, p. 55-67, ago. 2011.

RUSCHEL, M. E.; FREZZA, R.; UTZIG, M. J. S. O impacto do SPED na contabilidade desafios e perspectivas do profissional contábil. Revista Catarinense da Ciência Contábil, v. 10, n. 29, p. 09-26, 2011.

SANTOS, F.; GUSTAVO, L. Reportagem A transformação da Contabilidade em papel para a Contabilidade digital. Revista Brasileira de Contabilidade, n. 156, p. 14-21, 2005.

SCHIAVI, Giovana Sordi et al. No caminho da inovação: análise das capacidades de inovação de empresas contábeis diante das tecnologias digitais. Revista Brasileira de Gestão de Negócios, v. 22, n. 2, p. 381-405, 2020.

SEBOLD, M.; PIONER, L. M.; SCHAPPO, C.; PIONER, J. J. M. Evolução da contabilidade brasileira: do governo eletrônico ao sistema público de escrituração digital-SPED. Enfoque: Reflexão Contábil, v. 31, n. 2, p. 23-32, 2012.

SILVA, H. P.; LIMA, J. B. Governo Eletrônico e Informação Utilitária: uma relação necessária para uma efetiva inclusão digital. reposcom. portcom. intercom. org. br/bitstream/1904/16892/1/R2091-1. pdf Acesso em, v. 12, 2008. 
SILVA FILHO, G. M.; LEITE FILHO, P. A. M.; PEREIRA, T. R. L. Sistema público de escrituração digital: benefícios e dificuldades na visão dos operadores de contabilidade do município de João Pessoa. Revista Mineira de Contabilidade, v. 16, n. 3, p. 50-60, 2015.

TAVARES, H.; PEDRA, A. S. As obrigações tributárias acessórias e a proporcionalidade na sua instituição: uma análise a partir da teoria dos deveres fundamentais. Revista Tributária e de Finanças Públicas, a. 21, v. 109, mar./abr. 2013.

WERNKE, R.; BORNIA, A. C. A contabilidade gerencial e os métodos multicriteriais. Revista Contabilidade \& Finanças, v. 12, n. 25, p. 60-71, 2001. 